\title{
A PERIODIC COINTEGRATION MODEL OF QUARTERLY CONSUMPTION
}

\author{
PHIIIP HANS FRANSES AND TEUN KLOEK \\ Econometric Institute, Erasmus University, Rotterdam, P.O. Box 1738, NL-3000 DR, The Netherlands
}

\section{SUMMARY}

A periodic cointegration model is proposed to describe quarterly observed consumption. This model allows the cointegrating vectors and the adjustment parameters to vary with the seasons. Its links are discussed with an often considered standard economic theoretical model for macroeconomic variables like consumption. A simple empirical model specification strategy is given and applied to Austrian consumption and income data.

KEY WORDS time series; seasonality, periodic models

\section{INTRODUCTION}

Error correction models (ECMs) are regularly used to describe sets of macroeconomic time series variables, which concern for example consumption, unemployment and money demand. An important motivation for using error correction models is that they have strong links with economic theoretical models. Furthermore, an error correction model is useful in practical occasions since it assumes long-run relationships between trending time series variables, i.e. it assumes cointegration-see Engle and Granger ${ }^{1}$ for a discussion of the links between cointegration and error correction. Given that many macroeconomic time series like consumption and income are non-stationary in the sense that they contain a stochastic trend-see Nelson and Plosser ${ }^{2}$ inter alia-ECMs provide a useful theoretical and practical modelling framework.

Many applications of ECMs concem annually or quarterly observed time series, where the quarterly observations are usually considered in seasonally adjusted form. Recently, however, there has been a growing interest in constructing ECMs for quarterly time series in seasonally unadjusted form. The main reason for this is that there has been a growing consensus that seasonal fluctuations in quarterly time series are worthwhile to study in their own right, and that such fluctuations may convey information on the behaviour of economic agents-see Hylleberg ${ }^{3}$ and Miron. ${ }^{4}$ One such ECM which allows for an explicit description of seasonal fluctuations is the socalled seasonal cointegration model proposed by Engle et al., ${ }^{5}$ which is applied to describe consumption and income in Japan. This seasonal error correction model (SECM) extends the usual ECM by investigating the presence of long-run relationships between stochastic seasonal trends. As noted by Osbom, ${ }^{6}$ and as we indicate in Section 3 below, a drawback of the SECM is that it assumes that the cointegration relations vary with the lags, which may be hard to interpret

CCC 8755-0024/95/020159-08

(C) 1995 by John Wiley \& Sons, Ltd.
Received 29 September 1993 Revised 25 January 1995 
meaningfully in terms of economic theory. In this paper, therefore, the authors propose an altemative ECM for quarterly observed time series on consumption and income-the so-called periodic error correction model (PECM). This PECM extends the standard ECM by, for example, allowing the cointegration relations to vary with the seasons - see also Birchenhall et al. ${ }^{7}$ for an empirical model for consumption in the United Kingdom.

The outline of the paper is as follows. In Section 2, the authors sketch a theoretical economic basis for ECMs that is useful for modelling consumption. In Section 3, the ECM is extended in order to be able to describe seasonal fluctuations explicitly. Then the authors discuss the seasonal and the periodic ECMs. In Section 4, the authors we present a step-wise empirical model specification strategy for a PECM, thereby extending the material of Birchenhall et al. ${ }^{7}$ In Section 5, the authors apply this specification strategy to quarterly consumption and income data for Austria, 1954.1-1989.4. Finally, in Section 6, the paper is concluded with some remarks.

\section{ERROR CORRECTION MODELS}

An economic theoretical motivation for the empirically useful ECM is the so-called linearquadratic adjustment cost model (LQAC) - see Nickel1 ${ }^{8}$ and Gregory. ${ }^{9}$ Applications of LQAC models can be found in describing labour and money demand- see Sargent, ${ }^{10} \mathrm{Kennan}^{11}$ and Dolado $e t a l^{12}$-and in the present paper we assume the usefulness of this theoretical framework for modelling consumption.

Consider an economic time series $x_{t}, t=1, \ldots, n$, with its target value $x_{t}^{*}$, where the target is related to an $(m \times 1)$ vector of forcing explanatory variables $z_{t}$, or

$$
x_{i}^{*}=\theta^{\prime} z_{t}+u_{t}
$$

where $u_{t}$ is assumed to be a standard white noise process, i.e. a zero-mean uncorrelated process with constant variance. In this paper, $x_{t}$ is taken to be consumption and $z_{t}$ to be a univariate income series. Assume that at time $t$, economic agents choose the sequence $x_{t+j}$, with $j=0,1,2, \ldots$ in order to minimize the expected intertemporal loss function

$$
L_{t}=E\left[\sum_{j=0}^{\infty} \rho^{j}\left(\delta\left(x_{t+j}^{*}-x_{t+j}\right)^{2}+\left(x_{t+j}-x_{t+j-1}\right)^{2}\right)\right]
$$

where $E$ denotes the expectation at time $t$ on the basis of information set $I_{t}, \rho$ is a certain discount factor and $\delta>0$ is a weighting factor which reflects adjustment costs. The expression in (2) corresponds to a linear quadratic adjustment cost (LQAC) model-see Sargent ${ }^{10}$ and Gregory, ${ }^{9}$ inter alia. The first term in (2) concerns the adjustment to the target of $x_{t}$, and the second term reflects the adjustment costs.

To ensure the empirical usefulness of (2), we need to make additional assumptions on the time series process $z_{s}$. When we assume that these forcing variables can each be described by random walks, i.e. $\Delta_{1} z_{i t}=\varepsilon_{i t}$ for $i=1, \ldots, m$ and $\varepsilon_{t i}$ are each white noise error processes, with $\Delta_{1}$ defined by $\Delta_{k} x_{t}=\left(1-B^{k}\right) x_{t}=x_{t}-x_{t-k}$, it can be shown that the solution of the problem of minimizing $L$ in (2) can be represented by the ECM

$$
\Delta_{1} x_{t}=\alpha\left(x_{t-1}-\theta^{\prime} z_{t-1}\right)+\beta^{\prime} \Delta_{1} z_{t}+\varphi_{t}
$$

where $\varphi_{l}$ is again a white noise error process - see, for example, Gregory. ${ }^{9}$ In case the $\Delta z_{t}$ process can be described by some vector autoregressive process (VAR), (3) should be modified by including additional lags of $\Delta_{1} x_{t}$ and $\Delta_{1} z_{t}$. 
The $\alpha$ parameter in (3) is related to the $\delta$ parameter in (2) in the sense that if $\delta>0$ it holds that $a<0$. In case the time series $x_{t}$ and $z_{t}$ are both non-stationary, i.e. both time series contain a stochastic trend, the model in (3) assumes the presence of cointegration between $x_{t}$ and $z_{t}$-see Engle and Granger. ${ }^{1}$ The cointegration vector is $\left(1,-\theta^{\prime}\right)$. The adjustment parameters $\alpha$ 'correct' the errors from being out of equilibrium.

\section{SEASONAL AND PERIODIC ERROR CORRECTION}

In this section, two possible extensions are discussed of the ECM in (3), which can be considered when describing time series with pronounced and possibly non-constant seasonal fluctuations. Without loss of generality, we assume that $z_{t}$ is a univariate process for notational convenience. The first model we discuss is the seasonal error correction model (SECM), which has been proposed by Engle et al. ${ }^{5}$ The second is the periodic ECM.

\subsection{Seasonal error correction}

The SECM is motivated by the fact that quarterly observed time series may have stochastic trends at the non-seasonal and at the seasonal frequencies. Such a trend at the non-seasonal frequency, i.e. the familiar unit root 1 , can be removed using the first-order differencing filter. However, for quarterly time series, one may use the $\Delta_{4}=\left(1-B^{4}\right)$ filter-see Box and Jenkins. ${ }^{13}$ This fourth-order differencing filter can be decomposed as

$$
\begin{aligned}
\left(1-B^{4}\right) & =(1-B)(1+B)(1+\mathrm{i} B)(1-\mathrm{i} B) \\
& =(1-B)(1+B)\left(1+B^{2}\right) \\
& =(1-B)\left(1+B+B^{2}+B^{3}\right)
\end{aligned}
$$

where $i$ is defined by $i^{2}=-1$, and where $(1+B)$ corresponds to the seasonal unit root -1 and $\left(1+B^{2}\right)$ to the seasonal unit roots $\pm i$ - see Hylleberg et al. ${ }^{14}$ The seasonal unit roots correspond to the stochastic trends at seasonal frequencies. Hence, when a time series has seasonal unit roots, its seasonal fluctuations change over time. Hylleberg et al. ${ }^{14}$ have proposed a test strategy for the presence of seasonal unit roots.

In the case of multivariate time series, one may, similar to the non-seasonal cointegration case, investigate whether sets of time series have seasonal unit roots in common. In the case of two time series $x_{t}$ and $z_{t}$ that both need to be differenced by $\Delta_{4}$ and which are cointegrated at all non-seasonal and seasonal frequencies, the SECM can be written as

$$
\begin{aligned}
\Delta_{4} x_{t}= & \gamma_{11}\left[\left(1+B+B^{2}+B^{3}\right) x_{t-1}-a_{12}\left(1+B+B^{2}+B^{3}\right) z_{t-1}\right] \\
& +\gamma_{12}\left[\left(-1+B-B^{2}+B^{3}\right) x_{t-1}-\alpha_{22}\left(-1+B-B^{2}+B^{3}\right) z_{t-1}\right] \\
& -\left(\gamma_{13}+\gamma_{14} B\right)\left[\left(-1+B^{2}\right) x_{t-2}-\alpha_{32}\left(-1+B^{2}\right) z_{t-2}\right. \\
& -a_{41}\left(-1+B^{2} x_{t-3}-a_{42}\left(-1+B^{2}\right) z_{t-3}\right]+e_{t}
\end{aligned}
$$

where the notation is similar to that of Engle et al. ${ }^{6}$ The first cointegration term on the righthand side corresponds to cointegration at the non-seasonal frequency, the second and third terms to cointegration at seasonal frequencies. The adjustment parameters are $j_{1 j}$, with $\mathrm{j}=1,2,3,4$.

With respect to the target relation (1), the target relations in (5) are written in terms of transformed $x_{t}$ and $z_{t}$ series. For example, the target relation at the non-seasonal frequency equals $\left(1+\mathrm{B}+\mathrm{B}^{2}+\mathrm{B}^{3}\right) \mathrm{x}_{\mathrm{t}}^{*}=\mathrm{a}_{12}\left(1+\mathrm{B}+\mathrm{B}^{2}+\mathrm{B}^{3}\right) \mathrm{z}_{\mathrm{t}}$. In a comment on the work of Engle et al., ${ }^{5}$ 
Osborn ${ }^{6}$ demonstrates that (5) corresponds to

$$
\Delta_{4} x_{t}=\sum_{i=1}^{4} a_{i}\left(x_{t-i}-\theta_{i} z_{t-i}\right)+\varepsilon_{t}
$$

indicating that the SECM implies four different target relationships associated with different lags. Indeed, such parameter variation may be hard to interpret in terms of economic behaviour.

\subsection{Periodic error correction}

An alternative model for seasonal observed time series that explicitly takes into account the seasonal variation in such variables is the periodic ECM, a simple version of which is given by

$$
\Delta_{4} x_{t}=\sum_{i=1}^{4} \alpha_{s}\left(x_{t-4}-\theta_{s} z_{t-4}\right)+\beta \Delta_{4} z_{t}+\varepsilon_{t}
$$

where $\alpha_{s}$ and $\theta_{s}$ are periodically varying adjustment and cointegration parameters, respectively. There are four different target relations similar to (1) of the form $x_{t}^{*}=\theta_{s} z_{t}+u_{t}$, which in this case for the PECM vary with the season. These time-varying target relationships may originate from the time-varying availability of certain goods and services or from seasonally varying utility. Osbor ${ }^{15}$ has derived a univariate consumption model in which it is assumed that consumers have a periodically varying utility function. Hence, the model in (7) in a sense amounts to a multivariate extension of the Osborn model. ${ }^{15}$ Furthermore, seasonally varying adjustment parameters may reflect that adjustment is more easy in some seasons than in others. Additionally, economic agents may want to correct disequilibrium errors in some seasons more than in other seasons.

The model in (7) differs from most models for consumption which can be found in the literature, although it bears several similarities with the model due to Birchenhall et al. ${ }^{7}$ For example, the model of Davidson et al. ${ }^{16}$ assumes that $\theta_{s}=1$ and $\alpha_{s}=\alpha$ for all $\mathrm{s}$.

\section{AN EMPIRICAL MODEL SPECIFICATION STRATEGY}

In this section, an empirical model specification strategy is proposed for the PECM as in (7), possibly with the inclusion of additional lags of $\Delta_{4} x_{t}$ and $\Delta_{4} z_{l}$. This strategy follows the wellknown two-step strategy given by Engle and Granger, ${ }^{1}$ with one additional step for testing whether the various cointegration and adjustment parameter values are indeed periodically varying.

Consider the two quarterly observed time series $x_{t}$ and $z_{t}$ and the two $(4 \times 1)$ vector time series $X_{T}=\left(X_{1 T}, X_{2 T}, X_{3 T}, X_{4 T}\right)$ and $Z_{T}=\left(Z_{1 T}, Z_{2 T}, Z_{3 T}, Z_{4 T}\right)$, where $X_{s T}$ and $Z_{s T}$ are the observations on $x_{t}$ and $z_{t}$ in season $s$ and year $T$, where $T=1, \ldots, N$. Hence, the $X_{T}$ and $Z_{T}$ vector time series are observed annually. Periodic error correction as in (7) amounts to four cointegration relationships between $x_{t}$ and $z_{t}$, i.e. one cointegration relation per quarter. It is clear that these cointegration relations can be written as $X_{s T}-\theta Z_{s T}$ for $s=1,2,3,4$. A first step in specifying models like (7) is then to regress $X_{s T}$ on a constant and $Z_{s T}$ for each of the seasons. In case of cointegration between $X_{s T}$ and $Z_{s T}$, the residuals of one or more of these four regressions should be stationary time series. Of course, it can occur that only for a few seasons one obtains stationary residuals. In this case, the PECM can be called a partial PECM. 
When all four residual series are stationary, one has a full PECM.

To test for cointegration between $X_{s T}$ and $Z_{s T}$, we choose to check the value of the cointegrating regression Durbin-Watson $\left(\mathrm{CRDW}_{s}\right)$ statistic for each season $s$ and the Dickey-Fuller $\left(\mathrm{DF}_{s}\right)$ test. The asymptotic distributions of these test statistics can be derived from the asymptotic distributions in cases where the parameters do not vary over the seasons. This is caused by the orthogonality of the regressors. For example, the $\mathrm{DF}_{s}$ test should have the same distribution as the well-known cointegration Dickey-Fuller test in the case of two nonperiodic variables - see Engle and Granger. ${ }^{1}$ To verify these asymptotics, especially for small samples, we display some simulated critical values for these test statistics in Table $I$ for the cases where $z_{t}$ should be transformed using a $\Delta_{4}$ filter or a $\Delta_{1}$ filter. One can infer that the critical values for these two cases are similar and that the conjecture on the distributional results seem valid.

In case one obtains evidence that there is indeed cointegration in each season, a next step is to check whether the estimated parameters in the cointegration vectors, as well as the adjustment parameters, do indeed vary over the seasons. In other words, one may want to test the hypotheses $\theta_{s}=\theta$ and $\alpha_{s}=\alpha$. The test for $\theta_{s}=\theta$ can be performed by comparing the residual sums of squares (RSS) of the four regressions of $X_{s T}$ on a constant and $Z_{s T}$ with the RSS of the regression of $x_{t}$ on four seasonal dummies and $z_{t}$. Assuming cointegration, one can construct an $F$ test for the hypothesis $\theta_{s}=\theta$, which follows a standard $F$ distribution under the null hypothesis. This result follows from Theorem 3.1 due to Johansen. ${ }^{17}$ This test will be denoted as $F\left(\theta_{s}=\theta\right)$. Furthermore, in the case of cointegration, the $F$ test for the hypothesis that $\alpha_{s}=\alpha$ also follows a standard $F$ distribution, since $x_{t-4}-\hat{\theta}_{s} z_{t-4}$ are stationary variables-see Engle and Granger. ${ }^{1}$ This test will be denoted as $F\left(\alpha_{s}=\alpha\right)$. Similar test statistics can be constructed in case of partial instead of full PECMs, although one should then make sure that the $F$ tests for restrictions on the $\theta_{s}$ and $\alpha_{s}$ are only calculated for those seasons where one obtains cointegrating relationships. Otherwise these $F$ tests do not follow standard $F$ distributions.

Finally, a test for the weak exogeneity of $z_{t}$ for the cointegration relations can be performed via testing the significance of the periodic error correction variables in a model for $\Delta_{4} z_{r}$. Again, since these error correction variables are stationary variables, the relevant $F$ test follows a standard $F$ distribution under the null hypothesis-see Boswijk. ${ }^{18}$

Table I. Critical values of several test statistics for a sample of 25 years of quarterly observations, based on 20000 Monte Carlo replications $\dagger$

\begin{tabular}{|c|c|c|c|c|}
\hline \multirow[b]{2}{*}{ Test statistic } & \multicolumn{4}{|c|}{ Significance level } \\
\hline & $0 \cdot 20$ & 0.10 & 0.05 & 0.01 \\
\hline$\Delta_{4} z_{t}=v_{f}\left\{\begin{array}{l}\mathrm{CRDW}_{s} \\
\mathrm{DF}_{s}\end{array}\right.$ & $\begin{array}{r}0.86 \\
-2.70\end{array}$ & $\begin{array}{r}1.08 \\
-3 \cdot 13\end{array}$ & $\begin{array}{r}1 \cdot 26 \\
-3 \cdot 50\end{array}$ & $\begin{array}{r}1 \cdot 63 \\
-4 \cdot 27\end{array}$ \\
\hline$\Delta_{1} z_{l}=v_{1}\left\{\begin{array}{l}\mathrm{CRDW} \\
\mathrm{DF}_{s}\end{array}\right.$ & $\begin{array}{r}0.86 \\
-2.71\end{array}$ & $\begin{array}{r}1.09 \\
-3.12\end{array}$ & $\begin{array}{r}1.27 \\
-3.48\end{array}$ & $\begin{array}{r}1.63 \\
-4.31\end{array}$ \\
\hline
\end{tabular}

$\dagger$ The CRDW, for $s=1,2,3,4$, as well as the Dickey-Fuller $t$ test statistic $\mathrm{DF}_{\text {, }}$, for the null hypothesis of no cointegration are found by estimating the model: $X_{s T}=\mu_{s}+\theta_{s} Z_{s T}+\zeta_{b}$, for $s=1,2,3,4$, where $\Delta_{4} x_{t}=\varepsilon_{t}, \Delta_{4} z_{t}=v_{t}$ or $\Delta_{1} z_{t}=\psi_{1}$ and where $\varepsilon_{i}, v_{1} \sim N(0,1)$. 


\section{CONSUMPTION AND INCOME IN AUSTRIA 1954.1 TO 1989.4}

To illustrate the steps of empirically specifying a periodic cointegration model for consumption and income, we consider two time series for Austria. The series are real private consumption and real disposable income for the period 1954.1 to 1989.4 , which we use after taking natural logarithms. In 1964, the Austrian measurement system has been changed. Therefore, we ignore the observations for the period 1964.1 to 1965.1 by including five dummy variables in all forthcoming regressions. The estimation results for the periodic cointegration parameters $\theta_{s}$ and the related test outcomes are displayed in Table II. The values of the CRDW, and the DF, statistics indicate that the hypothesis of no cointegration can be rejected for three of the four quarters, and that the evidence for cointegration in quarter 1 is weak, though not extremely weak. Since the power of cointegration tests is usually low, especially for small samples, we assume the presence of cointegration in all four seasons.

The evidence in Table II suggests that the parameter values of $\theta_{s}$ can be different from 1 as well as from each other. The $F\left(\theta_{s}=\theta\right)$ test yields a value of 12.289 , which is significant at the $1 \%$ level. However, the $F$ test for the restriction $\theta_{1}=\theta_{2}=\theta_{4}$ obtains an insignificant value of 1.232. In sum, we restrict the periodic error correction term to ecm $x_{t}=x_{t}-\theta z_{t}-\theta_{3} z_{t}$.

An adequate periodic cointegration model as in (7) is found after a short search in which a general model is estimated, tested, and simplified. The model passes diagnostic checks for the presence of residual autocorrelation of order 1 and $4, \mathrm{ARCH}$ of order 1 and 4 , and normality. The simplified model for $\Delta_{4} x_{i}$ includes $\Delta_{4} x_{t-1}, \Delta_{1} \Delta_{4} x_{t-4}, \Delta_{4} z_{l}$, four error correction variables $\mathrm{ecm}_{t-4}$ for each of the seasons and four seasonal intercept terms corresponding to the error correction terms. The values of the $t$ statistics for the four $\alpha_{s}$ adjustment parameters are $-2.955,-4.382,-5.824$ and -4.452 for the four quarters, respectively. Compared with the standard normal distribution, these $t$ ratios suggest significant error correction in all four seasons. The $F\left(\alpha_{s}=\alpha\right)$ test gives a value of 2.205 , which is not significant at the $5 \%$ level.

Table II. Testing for cointegration per quarter between consumption $x_{t}$ and income $z_{t}$ in Austria for the sample 1954-1989 $(N=36)$

\begin{tabular}{lccc}
\hline Quarter & $\theta_{s}$ & $\mathrm{CRDW}_{s}$ & $\mathrm{DF}_{s}$ \\
\hline 1 & 0.944 & 0.623 & -2.387 \\
& $(0.012)$ & & \\
2 & 0.923 & 0.946 & $-3.433 \dagger$ \\
3 & $(0.010)$ & & \\
& 1.007 & $1.353 \ddagger$ & $-4.144 \ddagger$ \\
4 & $(0.008)$ & & \\
& 0.933 & $1.396 \ddagger$ & $-4.185 \ddagger$ \\
& $(0.010)$ & & \\
\hline
\end{tabular}

$\dagger$ Significant at a $10 \%$ level.

$\ddagger$ Significant at a $5 \%$ level.

Note. The $\theta_{s}$ refers to the estimated parameter for $Z_{s T}$ of the regression of $X_{s T}$ on 1 and $Z_{s T}$ per quarter s. Estimated standard emors are given in parentheses and should be treated with care since $\theta_{\text {, is a }}$ superconsistent estimator-see Engle and Granger. ${ }^{1}$ The CRDW, is the cointegrating regression Durbin-Watson statistic, and the DF, refers to the Dickey-Fuller $t$ ratio. The critical values of these statistics are displayed in Table I. 
Imposing the $\alpha_{s}=\alpha$ restriction, the final PECM for Austrian consumption is

$$
\begin{aligned}
\Delta_{4} x_{t}= & 0.114 D_{1 t}+0.107 D_{2 t}-0.053 D_{3 t}+0.156 D_{4 t}+0.374 \Delta_{4} z_{t} \\
& (0.014)(0.013)(0.009) \quad(0.019) \quad(0.071) \\
& +0.213 \Delta_{4} x_{t-1}-0.164 \Delta_{1} \Delta_{4} x_{t-4}-0.493\left[x-0.933 z-0.074 D_{3} z\right]_{t-4} \\
& (0.067)(0.053) \quad(0.062)(0.006)(0.013)
\end{aligned}
$$

where $D_{s t}$ is a seasonal dummy variable for season $s, s=1,2,3,4$. Model (8) is estimated for 144 observations, and the estimated standard errors are given in parentheses. Diagnostic test statistics indicate that this model cannot be rejected. Chow forecast tests, one-step-ahead forecast tests, CUSUM tests as well as the standard Chow split estimation tests do not indicate any severe misspecification.

Finally, we test for weak exogeneity of income for the parameters in the error correction part of (8). It appears that $\Delta_{4} z_{f}$ can be described by a first-order autoregressive model. Adding the error correction variables for each of the seasons yields an insignificant $F$ statistic of 0.655 . Hence, for this empirical example, we do not seem to need full system estimation methods like that in, for example, Johansen ${ }^{17}$

\section{CONCLUDING REMARKS}

In this paper, a periodic cointegration model has been proposed for quarterly consumption and income. This model allows that each quarter shows its own equilibrium relation between these variables, and that being out of equilibrium has distinct effects on future consumption. Hence this model may be rationalized using economic arguments such as that consumers have seasonally varying utility functions and adjustment costs within the theoretical framework of a linear quadratic adjustment cost model. An empirical specification strategy is discussed and applied to Austrian data on quarterly consumption and income. It appears that the proposed model gives a satisfactory description of the relations between these variables for Austria, and that the third quarter target relations for consumption relative to income is different from that in other quarters.

Extensions of the proposed model are the inclusion of deterministic trends, as well as more than two variables, into the periodically varying cointegration relations. Promising routes to test for cointegration seem to be given by extending the Boswijk ${ }^{18}$ or Johansen methods ${ }^{17}$. The effects of seasonal adjustment on estimating and testing for periodic cointegration, as well as on forecasting in cases where a periodic model is the most appropriate, are also worthwhile investigating. Finally, a topic for future research is to develop simple test procedures to select between seasonal and periodic cointegration models.

\section{ACKNOWLEDGEMENTS}

The authors wish to thank Peter Boswijk, Clive Granger, Niels Haldrup, Robert Kunst, Marius Ooms, Denise Osborn, participants of seminars at the University of Groningen, the Australian National University in Canberra, the University of Canterbury in Christchurch, ESEM91 in Cambridge and the European Winter Meeting of the Econometric Society (1991) for helpful suggestions. They also acknowledge the useful comments from an anonymous referee. Richard Paap provided excellent research assistance. The data used in this paper can be obtained from the first named author. All calculations were performed using MicroTSP (version 7.0). 


\section{REFERENCES}

1. R. F. Engle and C. W. J. Granger, 'Cointegration and error correction: representation, estimation, and testing,' Econometrica, 55, 251-76 (1987).

2. C. R. Nelson and C.I. Plosser, 'Trends and random walks in macroeconomic time series: some evidence and implications', J. Monetary Economics, 10, 139-162 (1982).

3. S. Hylleberg, 'Modelling seasonal variation', in C. P. Hargreaves (ed.), Nonstationary Time Series Analysis and Cointegration, Oxford University Press, Oxford, U.K., 1994.

4. J. A. Miron, 'The economics of seasonal cycles', in C. A. Sims (ed.), Advances in Econometrics, Sixth World Congress of the Econometric Society, Cambridge University Press, Cambridge U.K, 1994.

5. R. F. Engle, C. W. J. Granger, S. Hylleberg and H. S. Lee, 'Seasonal cointegration: the Japanese consumption function', J. Econometrics, 55, 275-298 (1993).

6. D. R. Osbom, 'Comment on Engle et al. (1993)', J. Econometrics, 55, 299-303 (1993).

7. C. R. Birchenhall, R. C. Bladen-Hovell, A. P. L. Chui, D. R. Osbom and J. P. Smith 'A seasonal model of consumption', Economic J., 99, 837-43 (1989).

8. S. Nickell, 'Enror correction, partial adjustment and all that: an expository note', Oxford Bull. Economics \& Statist., 47, 119-129 (1985).

9. A. W. Gregory, 'Testing for cointegration in linear quadratic models', J.Business \& Economic Statist., 12, $347-360$ (1994).

10. T. J. Sargent, 'Estimation of dynamic labour demand schedules under rational expectations', J. Political Economy, 86, 1009-1044 (1978).

11. J. Kennan, 'The estimation of partial adjustment models with rational expectations', Econometrica, 47, 1441-1455 (1979).

12. J. J. Dolado, J. W. Galbraith and A. Banerjee, 'Estimating Euler equations with integrated series', Int. Economic Rey., 32, 919-936 (1991).

13. G. E. P. Box and G. M. Jenkins, Time Series Analysis, Forecasting and Control, Holden-Day, San Francisco, 1970.

14. S. Hylleberg, R. F. Engle, C.W.J. Granger and B.S. Yoo, 'Seasonal integration and cointegration', J.Econometrics, 44, 215-38 (1990).

15. D. R. Osbom, 'Seasonality and habit persistence in a life cycle model of consumption', J. Appl. Econometrics, 3, 255-66 (1988).

16. J. E. H. Davidson, D. F. Hendry, F. Srba and S. Yeo, 'Econometric modelling of the aggregate time-series relationship between consumers's expenditure and income in the UK', Economic $J ., 88,661-692$ (1978).

17. $S$. Johansen, 'Estimation and hypothesis testing of cointegration vectors in Gaussian vector autoregressive models', Econometrica, 59, 1551-80 (1991).

18. H. P. Boswijk, H.P. 'Testing for an unstable root in conditional and structural error correction models', $J$. Econometrics, 63, 37-60 (1994). 